This is an electronic reprint of the original article. This reprint may differ from the original in pagination and typographic detail.

\author{
Author(s): Alcaraz-Quiles, Francisco J.; Urquia-Grande, Elena; Muñoz-Colomina, Clara I.; \\ Rautiainen, Antti
}

Title: $\quad$ E-government implementation : transparency, accessibility and usability of government websites

Year: $\quad 2018$

Version:

Please cite the original version:

Alcaraz-Quiles, F. J., Urquia-Grande, E., Muñoz-Colomina, C. I., \& Rautiainen, A. (2018). E-government implementation : transparency, accessibility and usability of government websites. In L. A. Muñoz, \& M. P. R. Bolívar (Eds.), International EGovernment Development (pp. 291-306). Palgrave Macmillan.

https://doi.org/10.1007/978-3-319-63284-1_12

All material supplied via JYX is protected by copyright and other intellectual property rights, and duplication or sale of all or part of any of the repository collections is not permitted, except that material may be duplicated by you for your research use or educational purposes in electronic or print form. You must obtain permission for any other use. Electronic or print copies may not be offered, whether for sale or otherwise to anyone who is not an authorised user. 


\title{
E-Government implementation: Transparency, accessibility and usability of government websites
}

\author{
Francisco J. Alcaraz-Quiles \\ Universidad de Granada \\ falacaraz@ugr.es \\ Elena Urquía-Grande \\ Universidad Complutense Madrid \\ eurquiag@ccee.ucm.es \\ Clara I. Muñoz-Colomina \\ Universidad Complutense Madrid \\ cimunoz@ccee.ucm.es \\ Antti Rautiainen \\ antti.i.rautiainen@jyu.fi \\ Jyväskylä University School of Business and Economics
}

\section{Introduction.}

The implementation of innovations in Internet technologies have become a key objetive in political agendas (Rodriguez et al., 2013; Jaeger and Bertot, 2010). So, the adoption of Information and Communication Technologies (ICTs), have caused a significant change in the relationships of governments with their different stakeholders (Osborne and Gaebler, 1992). This process of modernization has enabled a greater information accessibility and transparency. In this sense, initiatives such as, websites for public entities, data portals, social media tools, and online meetings and public feedback on public policies are playing a crucial role in order to promote the government transparency, participation, and collaboration (Jaeger and Bertot, 2010). Moreover, as highlighted International Transparency (IT, 2015), information and communication technologies (ICTS) has contributed to the adoption and dissemination of government transparency, providing relevant information in a timely, useful and comparable way and in an accessible format. In this line, Bannister and Connolly (2014) affirm that ICTs are a powerful tool to improve transparency.

In this context, different stakeholders and international institutions, in particular the European Union (EU) in their Directive 2011/85/EU (Council of Europe, 2011), are requiring public bodies to introduce information systems capable of providing the necessary transparency in all governmental levels: central, regional and local. Additionally, as pointed out (Lourenço et al., 2014) the promotion of sustainability activities and the publication of sustainability reports is recognised as a source of competitive advantage for the corporations.

Following the World Commission (1987), we can define sustainability as "equity between generations, i.e. meeting the [human] needs of the present without compromising the ability of future generations to meet their own needs". Internationally, the Global Reporting Initiative (GRI) guidelines are considered the standard of sustainability reporting, and are widely used as 
means of transparency on sustainability matters. In our study, transparency mean the disclosure of agendas and conditions, accompanied by the availability of full information required for collaboration, cooperation and collective decision making of regional managers. On the other hand, sustainability can be defined as the capability of local government to maintain, promote and preserve the social well-being of its citizens through the resources it has available, considering that this definition is suitable for measuring the degree to which a government fulfills the responsibilities it was established

In addition, accessibility to sustainable information from regional governments is defined in this work as the time used for achieving the sustainability information disclosed in governmental webs. We understand usability as the ease of use of governments' web page by users. In this sense, usability is measured in 12 items in line with Pina et al. (2007) embedding issues such as whether the Regional Government web page has a section for frequently asked questions, information in another language, current news section and glossary terminology, for example.

Contributing to earlier research methodologically, we have taken the Pina et al (2009) model to measure usability and the Alcaraz et al. (2014) model to measure GRI items disclosure, joined these models and added accessibility variables in order to analyze transparency in Regional Governments. Our combined or global model facilitates stakeholders to observe, compare and analyze the transparency information of Regional Governments, in order to improve the accountability of management and access of information for citizens.

Therefore, this book chapter seek to enhance the sustainability and accountability of Spanish Regional Government management and, secondly, to evaluate whether the reporting of the Spanish Regional Governments is transparent in terms of citizens' accessibility and usability, we have been run a multivariate analysis.

This chapter book will be structured as follows. In section two, a bibliography revision about these issues. Section three shows the sample selection and the methodology description. Finally, the last sections are empirical results and conclusions.

\section{Transparency of sustainable information in Regional Governments}

Concepts of sustainability and transparency are key issues for companies and for public entities to demonstrate their committed performance towards society (Rodriguez et al., 2013; Jaeger and Bertot, 2010). The concept of transparency means making something visible; instead of hiding for example the decision-making principles or performance indicator scores (see Roberts, 2009). Transparency is generally accompanied with a belief that transparency reveals the bad and helps to discover the good organizations, sub-units and managers (Roberts, 2009). For example, Angluin and Scapens (2000) suggest that high degree of transparency supports the perceived fairness of resource allocations. Focusing on transparency in web sites may facilitate analyses of information about internal work, decision processes and procedures (Pina et al. 2009). However, even clearly presented information is not necessarily fair, but transparency and has limits because the data presented may be inaccurate or 
symbolic, because there often exists several ways to present accounting data and account for costs, such as depreciation (Hines, 1988). In this line, Roberts (2009) suggests that full transparency is often a fantasy, especially if there is an attached belief that high degree of transparency automatically leads to increased accountability and effectiveness. Further, transparency may be used to produce guilt or blame in order to gain benefits in some personal or sub-unit power games, which lead to deterioration of the organizational or societal performance as a whole (Hood, 2007; Hopwood, 1972; Roberts, 2009). Thus, transparency is relatively difficult to assess, it is not just the visibility of the information but we may need to consider the quality (e.g. relevance, comparability and timeliness) of the information presented and the accessibility of this information. For example, disclosing information according to some standard, such as the GRI in this paper, can be considered relatively objective and value-neutral, improving both relevance and comparability as well as diminishing the potential to deliberately manipulate the presentation of sustainability information (see also Angluin and Scapens, 2000).

Further, the concept of accessibility refers to the ease with which different stakeholders can get their hands on the information. Accessibility may be judged based on whether the information is made visible, or access is denied (e.g. with a password) or if information is deliberately hidden, for example in the myriad of the internet pages of the company (see also Angluin and Scapens, 2000). Thus, regarding data on the internet we might analyze the time it takes for an educated internet user to find appropriate data from the internet pages of the organization in question. Thus a few key aspects, such as comparability and accessibility, may be assessed and then given a score or grade. For example, Angluin and Scapens (2000) used grades or categories of low, medium or high financial transparency. Such grades or overall scores may serve as a measure of the transparency of the information disclosed.

Following Pina et al. (2009), we measure usability using 12 items related with the easy of use of web pages of RGs. These items assets diverse aspects as the existence of sitemap, the availability of web in foreign languages or the existence of FAQ section in governmental web. Three of the items are specifically designed to know the online facilities for people with some kind of disability, for example, if the web provides audio access for the visually impaired. The results obtained for each RG web about usability, give us a measure of easy use of web from the standpoint of the perception of citizens that use the governmental web as a place to obtain public information.

Considering sustainability analysis, several researchers have proposed analysing the disclosure of governmental information about sustainability based on the GRI framework (Álcaraz-Quiles et al., 2014). The GRI includes 75 parameters divided in general, economic, social and environmental areas which aid measuring Regional Government sustainability. The GRI guidelines aim to advice organisations on how to provide comparable information about their activities in general, economic, social and environmental areas for the exchange of reliable and transparent information on sustainability (Lodhia et al., 2012).

Currently, Spanish Governments are making improvements in both informing citizens about their initiatives, activities and achievements and attaining more interaction with citizen 
suggestions. However, it is not known what kind of in information, and with what kind of transparency is disclosed, for example, by the regional governments in Spain regarding sustainability. In this research paper sustainability information will be measured by items selected from the GRI index in Spain.

Bearing all this in mind we define the following research questions:

RQ1: Has the implementation of e-government improved the transparency about sustainability in Spanish regional governments?

RQ2: Do the citizens perceive the advantages of implementation of e-government in terms of accessibility and usability of RGs webs?

RQ3: Is there any relation between transparency, accessibility and usability in RGs web?

\section{Sample description and methodology}

The promotion of innovation strategies is one of the cornerstones of the new place-based approach characterizing regional development interventions in the European Union (EU). The role of government institutions in this phase is to provide the adequate incentives for the development of effective collaborations among all stakeholders in the innovation system, setting the conditions for an "inclusive" approach (Rodriguez-Posé et al., 2014). Moreover, author as Charron (2016) affirm that in the EU, regions with greater autonomy have greater lobbying power and are better equipped to manage funds and to promote transparency.

The Spanish case is intriguing because it is a country with a relatively recent and on-going process of decentralization. The consensual politics of the transition to democracy prevented any party from imposing its initial preferences on territorial politics, leaving an ambiguous and open-ended constitutional settlement (Colomer 1998). the process of territorial reform has, over time, exerted important 'feedback effects' of desentralitation. But the devolution of competences had not been accompanied by an adequate transfer of fiscal resource (Verge, 2013). , decentralization increases the incentives of regional leaders to follow differentiated regional agendas by increasing their associated benefits and diminishing their potential costs (León, 2014).

In the particular case of Spain, there are 17 Regional Governments (RGs), with a high grade of autonomy, self-government, and resources managed. In addition to above, the Spanish RGs has suffered more markedly the crisis of public finances, maintaining high levels of debt and deficit. The report of IGAE (2013), shows that a $22.47 \%$ of total deficit is due of RGs, being a $1.5 \%$ of GDP. Moreover, the whole of Spanish RGs manages a $31.8 \%$ of Non Financial Public expense.

Finally, Spanish RGs have a peculiarity for their study: they are, at the same time, providers and funders of services. In this sense, are responsible of manage important services as health, education, environment or social issues. In the other hand, the RGs finance some services provided by local governments, as culture, sports, and the provision of infrastructures and equipments (León, 2014; Bäck et al, 2013). 
Therefore, the position of the Spanish RGs, dovetailing their proximity to stakeholders and their position as funder of local governments. The volume of public expenditure managed. And finally, scarcity of studies on e-government at regional level are the reasons that led us to research the 17 Spanish RGs.

As affirm author as Bertot et al., (2010), Jaeger and Bertot (2010), Meijer (2007), or La Porte et al. (2002), the webs offer a wide variety of advantages as transparency channel. First, the vast majority of government information is now born digital, and many users want access to it in electronic form. Second, the web also increased interest in accessing government information. Third, the information disclosed via web has greatly reduced the cost of collecting, distributing and accessing government information. Fourth, webs have made much easier create canals for interaction between stakeholders and administration. And at the end, governmental information must survive in an accessible format and location. So, following previous research (Alcaraz-Quiles et al., 2015; Navarro-Galera et al., 2016; Ortiz-Rodríguez et al., 2015) we have tested the web sites of 17 Spanish RGs using a list of 75 items based on GRI guidelines.

The levels of information disclosure can be calculated based on total GRI items or, in more detail, divided according to four GRI areas: Strategic and general information, Economic, Social, and Environmental. Internationally, the GRI guidelines are the standard report of sustainability. The GRI guidelines aim to advice organisations on how to provide comparable information about their activities in general, economic, social and environmental areas for the exchange of reliable and transparent information on sustainability (Lodhia et al., 2012).

The level of accessibility is measured by the time a citizen (or a researcher) consumes in finding (accessing) the information disclosed. However we have assumed the user (citizen or researcher) is not a specialized on and therefore has not an economic and financial education and has an average cultural education. The levels of usability are measured within 12 parameters in line with (Pina et al., 2009) (Annex I).

So, we have carried out a content analysis to assess, first, the information about sustainability disclosed; second, the accessibility of information; and third, the usability of web. This system of scoring give as a measure of degree of publication by an objective and transparent manner, and has been used in previous studies (Bastida and Benito, 2007; Pina et al., 2007).

Once obtained the scores for transparency, accessibility and usability, we have carried out a Spearman correlation rank analysis. This technique were used for cases and samples similar in many studies, as the best statistical means, to test variables where exists a rank order (Sánchez 2004; Rodriguez and Navarro, 2007).

\section{Analysis of results}

Table 1 shows the result of information disclosed, accessibility and usability. We can observe that Regional Governments strategic, general, economic, social and environmental information are above a $60 \%$ of disclosure. The majority of the social and economic indicators are disclosed while the environmental are the least to be disclosed (42,08\%). The RG that publish more information about GRI list of items is Andalusia (72\%), followed by Catalonia (70.67\%). The lower percentages of divulgation are for Balearic Island and Murcia (44\% and 40\%). 
In the case of accessibility, the access to strategic and general information is higher than access to economic or environmental, which indicates poor access to social information. We can realize a usual citizen takes more than an hour to search for any of the information. Concerning strategic and general information, which includes a total of 28 items including Regional Governments commitment, strategic lines and similar issues, a 60\%, was available but it took an average of three hours to find them. About the economic information where there are 24 items entangle an average of two hours and a half to find. With respect to social information, it took an average of one hour to find them. It is interesting to observe this section is the easiest to access maybe because it embeds also the easiest information to look for a usual citizen. Regarding the environmental information which includes 12 items, there is little information disclosed and it consumes two hours approximately to find it. The strategic and general information and economic information are the fastest information found while in the case of environmental information the citizens have to spend more time to find each item. The RGs most accessible are Valencia and Extremadura (50 and 75), while the citizens of Basque Country and Castilla La Mancha have to spend more time looking for information in the governmental webs (140 and 130).

The average of usability indicates than users of web page appreciate the ease of use of the web by just over half (62.75\%). The RGs with webs more usable are Andalusia and Galicia (10). In the other part, the webs with a lower punctuation in usability are Extremadura, Balearic Island, and Castilla Leon (4). The averages and standard deviation have been calculated in Table 1.

(Table 1)

In a starting analysis, Andalusia is the RG most transparent, and has the first position in usability, with an intermediate position in accessibility. In the other hand, Balearic Islands is the RG fewer transparent, and has last position in usability, being positioned in the fourth quartile in accessibility. Additionally, Extremadura is the second one in time used in searching information (accessibility), but has the perception of usability by users of web lowest.

(Table 2)

The statistical data analysis was made with SPSS 22. Because we have a small sample limitation we have done two complementary tests: Spearman and Kendall. In both of them the results are similar. We have carried out the test comparing, individually the percentages of transparency obtained, both total and for each information category determined, with the total value obtained in accessibility, and the values obtained in accessibility in each one of the block of information. There is only one significative relation, general information disclosure level is inversely related to the citizens' accessibility to the Regional Government web page. This means that strategic and main objectives information is given but the citizens have to spend a lot of time in looking for. On the other hand, total information disclosure of GRI items is positively related to web usability. Although the time spent accessing information is high, citizens perceive that the web is ease of use. The remaining relations are not significative, also the relation between Accesibility and Ussability. 


\section{(Tables 3-5)}

\section{Discussion}

Regional Governments accountability is doubtful because although an average of a sixty percent of the information searched from the strategic, economic, social and environmental context was found it took an average of three hours to access to it. The complexity of understanding both the strategic and economic information increased the complexity of accessing it, so the time taken to access these two areas cannot be related to the time consumed in accessing the social and environmental areas. In general the GRI issues have a high component of complexity which justifies the high time consumption it took to find many of the issues.

We have found real difficulties to find the environmental information opposite to ÁlcarazQuiles et al. (2014), who found many environmental indicators at an international level. This difficulty may be due to great increased of environmental information, establishing RGs specific websites for this type of information, and disclosing in the RG official website only a small part of the whole environmental information. Moreover, in line with the results obtained by Navarro-Galera et al. (2016), social information is the most widely disclosed, highlighting the commitments of the regional administration in this type of information. The priority for disclosing social information could be the response of RGs of demands of stakeholders with specials needs.

In general, and with the exception of environmental information, the time spent to find information exceeds amply the amount of this kind of information published on the web. In addition, environmental information is that which has a greater ratio time spent by item. Therefore, although the information exists on the web, it is necessary to spend too much time to find it.

As regards of the usability of web, users generally perceive that the web has an easy use, increasing this perception when the volume of information disclosed is greater. Our findings corroborated the results obtained by authors as Pina et al. (2007), associating high degrees of transparency with high web usability.

\section{Conclusions}

Governments worldwide recognize that ICTs is a way of enhancing citizen trust in governments. Most of the web sites analysed are dissemination a great average of information. In this chapter book, we try to know if the implementation of e-government initiatives in the application of ICTs, has some effects on transparency, accessibility and usability on Spanish RGs web sites.

Contributing to earlier research methodologically, we have taken the Pina et al (2009) model to measure usability and the Alcaraz et al. (2014) model to measure GRI items disclosure, joined these models and added accessibility variables in order to analyze transparency in Regional Governments. Our combined or global model facilitates stakeholders to observe, compare and analyze the transparency information of Regional Governments, in order to improve the accountability of management and access of information for citizens. 
The implementation of E-government in an opportunity and has huge potential to contribute to the modernization of government. It could increase the contribution of web sites as a way to increasing transparency, accessibility and usability.

Our results show that the transparency of web sites of RGs is inversely related with the accessibility. The information is available but you have to spend too much time to find it. Nevertheless, the transparency is positively related with usability, so, the users of web site with a greater percentage of information disclosed, have the perception that web sites achieve the standards of usability; anyone could easily navigate in it. The web sites of RGs offer an easy way to access and navigate by them.

As regards of the perception of citizens, the RGs more transparent about sustainability are those which have to spend more time to access of information, a poor accessibility. In the opposite hand, the RGs more transparent about sustainability are those which have the best usability.

Limitations to the research work are the accessibility was measured in minutes taken to find the different GRI issues but it should be reclassified in a Likert way being the highest punctuation to the lowest rank of time taken to access any GRI items while the lowest punctuation would be given to the highest time consumption in accessing the GRI items.

For further research in this area, we believe it necessary to extend the scope of the statistical study, complementing it with the analysis of other variables of population, political and financial nature, and comparing these results with those obtained in other fields. It would also be interesting to compare these results with those for other levels of government, both local and national. 


\section{References}

Alcaraz-Quiles, Navarro-Galera \& Ortiz-Rodríguez (2014) A comparative analysis of transparency in sustainability reporting by local and regional governments. Lex Localis, 12 (1), 55-78.

Angluin, D. and Scapens, R. (2000) Transparency, Accounting knowledge and perceived fairness in UK universities' resource allocation: results from a survey of Accounting and finance. British Accounting Review, 32 (1), 1-42.

Bannister, F. and Connolly, R. (2014) ICT, public values and transformative government: A framework and programme for research. Government Information Quarterly, 31(1), 119-128.

Bastida, F. y Benito, B. (2007). Central government budget practices and transparency: an international comparison. Public Administration, 85(3), 667-716.

Bertot, J. C., Jaeger, P. T., and Grimes, J. M. (2010). Using ITCs to create a culture of transparency: E-government and social media as openness and anti-corruption tools for societies. Government Information Quarterly, 27, 264-271.

Council of Europe (2011). Council Directive 2011/85/EU of 8 November 2011 on requirements for budgetary frameworks of the Member States. Available at: http://eurlex.europa.eu/LexUriServ/LexUriServ.do?uri=OJ:L:2011:306:0041:0047:en:PDF

Charron, N. (2016). Quality of government, regional autonomy and Cohesion policy allocations to EU regions. In Handbook on cohesion policy in the EU, Piattoni, S. and Polverari, L. (Eds), pp 92-106. Edward Elgar publishing Limited: Cheltenham.

Hines, R. (1988) Financial Accounting: in communicating reality, we construct reality. Accounting, Organizations and Society, 13 (3), 251-261.

Hood, C. (2007) What happens when transparency meets blame avoidance? Public Management Review, 9 (2), 191-210.

Hopwood, A. (1972) An empirical study of the role of Accounting data in performance evaluation. Journal of Accounting Research, 10, 156-182.

IGAE (2013). Avance actuación económica y financiera de las Administraciones Públicas, Madrid, IGAE. Available at: http://www.igae.pap.minhap.gob.es/sitios/igae/esES/ContabilidadNacional/infadmPublicas/Documents/Informes\%20Anuales/Avance_AAPP_201 3.pdf

International Transparency (IT) (2015). Índice de Transparencia de las CCAA. Available at: http://www.transparencia.org.es/

Jaeger, P. T., and Bertot, J.C. (2010). Transparency and technological change: Ensuring equal and sustained public access to government information. Government Information Quarterly, 27, 371-376. 
La Porte, T. M., Demchak, C. C., and de Jong, M. (2002). Democracy and bureaucracy in the age of the web. Empirical findings and theoretical speculations. Administration \& Society, (34), 411-446.

León, S. (2014) How does decentralization affect electoral competition of state-wide parties? Evidence from Spain. Party Politics, 20(3), 391-402.

Lodhia, S., Jacobs, K. and Park, Y.J. (2012) Driving public sector environmental reporting. Public Management Review, 14 (5), 631-647.

Lourenço, I. C., Callen, J. L., Branco, M. C. and Curto, J. D. (2014) The value relevance of reputation for sustainability leadership. Journal of Business Ethics, 119(1), 17-28.

Meijer, A. J. (2007). Publishing public performance results on the Internet. Do stakeholders use the Internet to hold Dutch public service organisations to account?. Government Information Quarterly, 24, 165-185.

Navarro-Galera, A. Alcaraz-Quiles, F. J. and Ortiz-Rodríguez, D. (2016). Online dissemination of information on sustainability in Regional Governments. effects of technological factors. Government information Quarterly, 33(1), 53-66.

Ortiz-Rodríguez, D., Navarro-Galera, A. and Alcaraz-Quiles, F. J. (2015). The influence of administrative culture on sustainability transparency in European Local Governments. Administration and Society, DOI: 10.1177/0095399715616838.

Osborne, D. and Gaebler, T. (1992) Reinventing Governemnt: Go to the entrepreneurial Spirit is transforming the public sector. Penguin: New York.

Pina, V.; Torres, L. and Royo, S. (2007). Are ICTs improving transparency and accountability in the EU regional and local governments? An empirical study. Public Administration, 85(2), 449472.

Pina, V.; Torres, L. and Royo, S. (2009). E-government evolution in EU local governments: a comparative perspective. Online Information Review, 33 (6), 1137-1168.

Roberts, J. (2009) No one is perfect: the limits of transparency and an ethic for 'intelligent' accountability. Accounting, Organizations and Society, 34 (8), 957-970.

Rodríguez Bolívar, M. P., Alcaide Muñoz, L. and López Hernández, a. M. (2013) Determinants of Financial Transparency in Government. International Public Management Journal, 16(4), 557602.

Rodríguez-Posé, A, di Cataldo, M. and Rainoldi, A. (2014). The Role of Government Institutions for Smart Specialisation and Regional Development. Joint Research Centre: Luxembourg.

Rodríguez Bolivar, M.P. and Navarro Galera, A. (2007). Could fair value accounting be useful, under NPM models, for users of financial information?. International Review of Administrative Sciences, 73(3), 473-502. 
Sánchez, J. (2004). Introducción a la Estadística Empresarial. Available at:

http://www.eumed.net/cursecon/libreria/index.htm

Verge, T. (2013) Party Strategies on Territorial Reform: State-wide Parties and the State of Autonomies in Spain. West European Politics, 36(2), 317-337.

World Commission (1987). Report of the World Commission on Environment and Development: Our Common Future. Available at: http://www.un-documents.net/our-common-future.pdf

Table 1: Descriptive analysis of GRI items disclosed, accessibility and usability.

\begin{tabular}{|l|c|c|c|c|c|}
\cline { 2 - 6 } \multicolumn{1}{c|}{} & \multicolumn{4}{c|}{ INFORMATION DISCLOSED (\%) } \\
\cline { 2 - 6 } \multicolumn{1}{c|}{} & TOTAL & Strategic \& General & Economic & Social & Environmental \\
\hline Average & $57,25 \%$ & $60,08 \%$ & $60,05 \%$ & $62,35 \%$ & $42,08 \%$ \\
\hline Std.Deviation & 0,0997 & 0,1350 & 0,1113 & 0,1147 & 0,2055 \\
\hline
\end{tabular}

\begin{tabular}{|l|c|c|c|c|c|}
\cline { 2 - 6 } \multicolumn{1}{c|}{} & \multicolumn{5}{c|}{ ACCESSIBILITY } \\
\cline { 2 - 6 } \multicolumn{1}{c|}{} & TOTAL & Strategy \& General & Economic & Social & Environmental \\
\hline Mean Total time & 514 & 180 & 152 & 71 & 110 \\
\hline Minutes by item & 8,4253 & 6,4433 & 6,3407 & 7,1176 & 8,4751 \\
\hline Std.Deviation & 66,6591 & 24,6477 & 31,8478 & 15,7331 & 21,5355 \\
\hline
\end{tabular}

\begin{tabular}{|l|c|}
\cline { 2 - 2 } \multicolumn{1}{c|}{} & USABILITY \\
\hline Average & $62,75 \%$ \\
\hline Std.Deviation & 2,0346 \\
\hline
\end{tabular}


Table 2. Scores obtained by RGs in Transparency, Accessibility and Usability.

\begin{tabular}{|c|r|r|r|}
\cline { 2 - 4 } & Transparency & Accessibility & Usability \\
\hline Andalusia & $\mathbf{7 2 , 0 0 \%}$ & 116 & $\mathbf{1 0}^{\mathbf{1}}$ \\
\hline Catalonia & $\mathbf{7 0 , 6 7 \%}$ & 120 & 9 \\
\hline Aragób & $69,33 \%$ & 117 & 7 \\
\hline La Rioja & $68,00 \%$ & 99 & 8 \\
\hline Valencia & $64,00 \%$ & $\mathbf{5 0}$ & 9 \\
\hline Madrid & $62,67 \%$ & 124 & 9 \\
\hline Navarra & $61,33 \%$ & 100 & 9 \\
\hline Basque Country & $61,33 \%$ & $\mathbf{1 3 0 ^ { 2 }}$ & 9 \\
\hline Castilla la Mancha & $58,67 \%$ & $\mathbf{1 4 0}$ & 7 \\
\hline Galicia & $56,00 \%$ & 121 & $\mathbf{1 0}$ \\
\hline Canary islands & $52,00 \%$ & 127 & 9 \\
\hline Castilla Leon & $49,33 \%$ & 121 & $\mathbf{4}^{\mathbf{2}}$ \\
\hline Asturias & $48,00 \%$ & 118 & 7 \\
\hline Cantabria & $48,00 \%$ & 103 & $6^{\mathbf{2}}$ \\
\hline Extremadura & $48,00 \%$ & $\mathbf{7 5}$ & $\mathbf{4}^{\mathbf{2}}$ \\
\hline Balearic Islands & $\mathbf{4 4 , 0 0 \%}$ & 103 & $\mathbf{4}^{\mathbf{2}}$ \\
\hline Murcia & $\mathbf{4 0 , 0 0 \%}$ & 109 & $\mathbf{7}$ \\
\hline
\end{tabular}

1. In grey color and bold the RGs more transparent, accessible and usable.

2. In italic and bold the RGs less transparent, accessible and usable.

Table 3. Spearman correlations among GRI indicators disclosure and accessibility

\begin{tabular}{|l|c|c|c|}
\hline \multicolumn{1}{|l|}{ Spearman R } & T(N-2) & p-level \\
\hline TOTAL & $-0,4093$ & $-1,7376$ & 0,1027 \\
\hline Strategy\&General & $-0,5626$ & $-2,6357$ & $\mathbf{0 , 0 1 8 7 ^ { * }}$ \\
\hline Economic & $-0,1105$ & $-0,4308$ & 0,6726 \\
\hline Social & $-0,3519$ & $-1,45632$ & 0,1659 \\
\hline Environmental & 0,0519 & 0,2015 & 0,8429 \\
\hline
\end{tabular}

Table 4. Spearman correlations among GRI indicators disclosure and usability Spearman R $\mathbf{T}(\mathrm{N}-2)$ p-level

Total Information discliosed-Usability $0,6407 \quad 3,2320 \mid \mathbf{0 , 0 0 5 6 ^ { * }}$


Table 5. Spearman correlations among Accesibility and usability

Spearman R T(N-2) p-level

\begin{tabular}{|l|l|l|l|}
\hline Accesibility- Usability & $-0,4743$ & $-2,087$ & 0,0544 \\
\hline
\end{tabular}

ANNEX 1

USABILITY

Is there any acccess in other languages?

Is there are glossary with difficult technicisms?

Is there any section for news?

Is there a web map?

Alphabetical order

FAQ

Search Engine Motors

Is there any offer to access to specialised databases (Law, Economics or similar)?

Is there any uniformity among its pages

Does it proporcionate a text version or an accesible web site?

Does it have a listening version for vision impaired?

Does it show any icons of approval which guarantee access rules? 